\title{
RESEARCH ANALYSIS ON MOOC COURSE DROPOUT AND RETENTION RATES
}

\author{
Dr. Marcela Gerogina GOMEZ-ZERMENO \\ Tecnológico de Monterrey, School of Education, \\ Humanities and Social Sciences, Monterrey, MEXICO \\ Lorena ALEMAN DE LA GARZA \\ Tecnológico de Monterrey, School of Education, \\ Humanities and Social Sciences, Monterrey, MEXICO
}

\begin{abstract}
This research's objective was to identify the terminal efficiency of the Massive Online Open Course "Educational Innovation with Open Resources" offered by a Mexican private university. A quantitative methodology was used, combining descriptive statistics and probabilistic models to analyze the levels of retention, completion, and desertion, as well as the characteristics of the students who completed the course. The results show a $14 \%$ of student retention and an $\mathbf{1 1 . 7 \%}$ of student completion, relative to the total number of participants, who had some common characteristics: having a graduate (master or doctorate), being experienced in online education, committed to the course and self-taught. The participants who abandoned the course expressed the following reasons: problems with the course's structure, limitations in the use of information and communication technologies or limited English proficiency, family reasons or low time disposition. It is recommended to take actions that will increase the knowledge in order to explain the MOOCs' desertion rates and to strengthen their structures to improve the retention and completion rates.
\end{abstract}

Keywords: Distance education, Open educational resources, MOOC, Terminal efficiency, School desertion

\section{INTRODUCTION}

The evolution of distance education and technological advances signify an important opportunity to increase education's access and contribution to the compliance of international commitments regarding education. In this respect, the United Nations Educational, Scientific, and Cultural Organization (UNESCO, 2002, 2012) has established that free access to educational resources is a strategy to upgrade the quality of education, to facilitate the dialogue about policies, to interchange knowledge and to develop skills.

Massive Online Open Courses (MOOC) are an emerging practice in open learning. It began in 2008, when George Siemens and Stephen Downes offered the course Connectivism and Connective Knowledge in the University of Manithoba in Canada; the course had a duration of 12 weeks and 2,300 students enrolled (Fini, 2009; Wiley \& Hilton III, 2009).

Among their characteristics, MOOCs allow the construction of bonds between hundreds or even thousands of students who self-organize their participation, learning goals, knowledge, 
abilities and interests (McAuley, Stewart, Siemens \& Cormier, 2010). Additionally, their free online access enables the enrollment of a large number of students (SCOPEO, 2013).

Currently, Coursera, EdX, and Udacity are among the platforms that host MOOCs. For Latin American participants, MiriadaX and RedunX are available (Lushnikova, Chintakayala, Rodante, 2013; SCOPEO, 2013). Many Latin American universities have developed their own MOOCs in their institutional platforms or even through social networking sites such as Facebook. Nevertheless, only three Latin American universities are part of the Coursera community.

In developing countries, the use of MOOCs is an alternative educational offering for professionals who look for complementary training and education. In addition, these courses allow the acquisition of new knowledge and skills in fields that could provide them the opportunity for a better income or to continue learning throughout life. Massive courses attract thousands of participants who are interested in the offered topic; however, it is important to note that approximately only $10 \%$ of the registered students complete the course (Lushnikova et al., 2013). Such case is reported by the University of Toronto (Harrison, 2013), where the percentage of terminal efficiency varied between $3 \%$ and $16 \%$. On a similar note, SCOPEO (2013) reported an average of $13.5 \%$ of students who completed the course, out of 188,802 registered participants in $\mathbf{5 8}$ courses from 18 universities.

The low terminal efficiency rates of MOOCs reveal a lack of self-regulation and self-motivation in students (Lushnikova et al., 2013). Likewise, Clow (2013) remarks that the student's compromise level may diminish as the courses move forward. On this respect, Siemens and Tittenberg (2009) established that desertion rates could be minimized by providing more attention to the students regarding the components of effective learning, motivation, institutional support and free access to educational resources, in order to promote the development of interpersonal relationships among peers, faculty, and teaching staff.

A dropout in online courses refers to the persons who inconspicuously discontinue their participation in the course; however, they are different from passive participants, students who do not unregister and continue the course without active collaboration in it (Rodríguez, 2012). Additionally, the author signals that the desertion rates and passive behavior of some MOOCs' participants are among the educators' concerns.

In Latin America, experiences related to MOOCs are still developing; due to the growing research demand for these educational practices, it is necessary to identify and overcome the difficulties and obstacles in order to increase their dissemination and implementation, as well as the promotion of this type of initiatives, so they can be integrated in the public agenda of countries, institutions and inter-institutional projects in Latin America (Mortera, 2012). These circumstances have been confirmed by Liyanagunawardena, Adams and Williams (2013), who signal a lack of research and information about MOOCs that can explain why participants do not complete a course.

According to Gómez-Zermeño (2012), it is important to create a context that supports innovative practices to evaluate the results of the undertaken efforts when new ways of teaching and learning are promoted. Given the research demands about the potentialities of MOOCs, it is important to inquire into the terminal efficiency of an MOOC offered in Spanish. This investigation generated information about the MOOC Educational Innovation through Open Resources, offered in Coursera on September of 2013. The study had the following research questions: What was the terminal efficiency of participants in the course Educational Innovation through Open Resources? What are the characteristics of the participants who successfully completed the course? With a quantitative methodology that combines 
descriptive and econometric statistics, the research results show the retention and terminal efficiency rates of the course, the features of students who completed the course, as well as the causes of dropout and abandonment. A probabilistic model was used to identify the weight of each one of the dropout factors and thus evaluate the terminal efficiency of the MOOC "Educational Innovation through Open Resources".

\section{RESEARCH METHOD}

Based on the research questions, the study opted for a quantitative methodology, combining the use of descriptive and econometric statistics, which allowed to identify the MOOCs' participants profile and to calculate the dropout rates and terminal efficiency. Probabilistic models were used to identify the weight of each one of the dropout factors. The dependent variable is a binary variable (if the student abandoned the course, it was assigned the value of 1 and 0 on the contrary) and the independent or explanatory variables include factors such as gender, age, previous experience in virtual education and electronic media, educational level, English proficiency, and intrinsic characteristics such as being proactive, innovative and selftaught.

The quantitative approach was used to analyze information through statistical methods; participants answered a diagnostic and final survey to inform about their opinions and perspective, this allowed understanding better the numerical data. Recognizing the participants' experiences allowed the comprehension of the phenomenon (Alemán \& GómezZermeño, 2012; Gómez-Zermeño, Rodríguez Arroyo \& Márquez Guzmán, 2013).

From an explanatory point of view (Creswell \& Plano, 2011), the study sought to understand why the dropout phenomenon occurs and under what conditions, in order to identify the reasons why MOOC's participants decide to dropout and not complete the course. We used a non-experimental, cross-section and ex-post-facto design, and the participants' information was collected during August-September of 2013 (Valenzuela y Flores, 2012).

\section{MOOCS's Description and Context}

The MOOC "Educational Innovation through Open Resources", offered in Coursera, can be catalogued as continuous training; although it's access was not restricted, it was designed mainly for basic education teachers in Mexico. Two Head Professors who have ample experience in the design of online courses, the use of Open Education Resources and Educational Technology designed it. The context of the MOOC's creation is within a prominent Mexican University, leader in Educational Technology and the first Mexican University to impart courses via satellite in the mid 90's. This University has offered online courses through their virtual campus for over 20 years.

The course covers the subject of the selection, use and reuse of open educational resources, the possibilities the repositories that house these materials have, search strategies and integration into educational processes, as well as measuring and assessing their impact on learning of the participants. Thus, the participant would develop digital skills and instructional design skills to integrate open educational resources (OER) in their learning environments through open educational practices.

In four modules, participants were able to watch videos or read about the course's topics, and interacted with other participant in discussion boards by answering opinion questions. Digital portfolios and self and peer evaluations were used to assess the students' understanding of how to integrate OER in institutional and learning processes in their own learning environment. 
Research Population and Sample

According to the statistics provided by the platform, 20,400 people registered for the course, which started in September of 2013. From the initial population, 4,407 participants completed the instrument called, "Pre-diagnosis survey" and 3,547 people answered the "Initial survey." The data of each participant was given a unique identification code, which cannot be duplicated; by combining these two registers, we obtained 5,854 participants who were considered as the study sample. Table 1 shows the results of both surveys.

Table: 1

Results from Pre-diagnostic and Initial Survey

\begin{tabular}{lrr}
\hline Instrument & Participants & $\%$ \\
\hline Pre-diagnostic survey & 2,307 & 39.4 \\
Initial survey & 1,447 & 24.7 \\
Both instruments & 2,100 & 35.9 \\
Participants of the research population & 5,854 & 100.0 \\
\hline
\end{tabular}

Considering the information of 5,854 out of 20,400 people who registered, it was important to confirm if the number of existing cases permitted a statistical analysis in order to identify significant differences among the constructs. The formula to calculate the sample of finite populations was used; in Social Sciences research, the maximum sampling error is $5 \%$, and although this data was not available, 5,854 of the participants who completed either the prediagnosis or the initial survey correspond to a sampling error of $1.2 \%$, considered statistically significant.

\section{Instruments}

The data collection instruments were created by the head professors of the MOOC; there following 6 surveys were applied and used for collecting data:

$>$ Pre-diagnosis survey: is a structured questionnaire with 49 questions, combining closed questions, multiple options and weighted options using Likert rating scale. This instrument collects information about: general student data, MOOCs perceptions, skills and knowledge of information technologies, use of search engines, use of OER, Innovation and open education movement,

$>$ Initial survey: collects general information on participants such as age, sex, marital status, country of residence, education, experience in online education, computer and internet connection type, social networks used, among others. Additionally, survey asked about the reasons for registering in the course, the level of commitment and hours per week to devote to the course.

$>$ Topic 1 self-assessment: 15 multiple choice questions regarding the topic 1 Open educational movement.

$>$ Topic 2 self-assessment: 15 multiple choice questions regarding the topic 2 Search of educational resources.

$>$ Topic 3 self-assessment: 15 multiple choice questions regarding the topic 3 Use of open educational resources in learning processes.

$>$ Topic 4 self-assessment: 15 multiple choice questions regarding the topic 4 Mobilization of open educational resources in learning environments.

These instruments do not have psychometric test results and do not correspond to an evaluation research design, but rather an exploratory design. They were completed online by participants using the platform Coursera. 


\section{Research Procedure}

During the first week of the course, the pre-diagnosis and initial electronic surveys were administrated; a link was provided thru the platform, and e-mail notification was sent to all the registered participants. The instruments were completed virtually and voluntarily; the results show that more than $\mathbf{7 0 \%}$ of the enrolled students did not answer the surveys.

The self-assessment instruments for topics 1 to 4 were provided at the end of each week thru a direct link. As the course moved forward, the number of participants who completed the instruments decreased. Table 2 shows that at the end of the first week, $30 \%$ of the participants delivered evidence of their work, which diminished to a $\mathbf{1 5 . 6 \%}$ in the last week of the course.

Table: 2

Level of participation throughout the course

\begin{tabular}{ccc}
\hline Instrument & Participants & $\%$ \\
\hline Research population & 5854 & $100.0 \%$ \\
Topic 1 Self-assessment & 1779 & $30.4 \%$ \\
Topic 2 Self-assessment & 1165 & $19.9 \%$ \\
Topic 3 Self-assessment & 967 & $16.5 \%$ \\
Topic 4 Self-assessment & 911 & $15.6 \%$ \\
\hline
\end{tabular}

\section{RESULTS ANALYSIS}

Using a quantitative method, in this research, descriptive and econometric statistics were used to calculate the retention and terminal efficiency rates of the course, to identify the features of students who completed the course, as well as the causes of dropout and abandonment. Finally, a probabilistic model was created to identify the weight of each one of the dropout factors and thus evaluate the terminal efficiency of the MOOC "Educational Innovation through Open Resources".

\section{Retention and Terminal Efficiency Rates}

The databases were processed in SPSS (Statistical Package for the Social Sciences) and STATA, in order to calculate the MOOCs' retention rate by dividing the number of participants who completed the last self-assessment (Topic 4) by the total number of students who fulfilled the first instruments (pre-diagnosis and initial survey).

Table 3 shows the retention and terminal efficiency results of the MOOC, regarding the gender and total participants. $14.5 \%$ of retention was reported, meaning 818 participants who remained engaged until the last week of the course; while $11.7 \%, 683$ participants, delivered all four topic's self-assessments.

Table: 3

Terminal efficiency according to gender

\begin{tabular}{lllll}
\hline Efficiency & Female & Male & Total percentage & $\begin{array}{l}\text { Total } \\
\text { number }\end{array}$ \\
\hline Desertion & $\mathbf{8 2 . 2 \%}$ & $\mathbf{8 2 . 4 \%}$ & $\mathbf{8 6 . 0} \%$ & $\mathbf{5 , 0 3 6}$ \\
Retention & $17.8 \%$ & $17.6 \%$ & $14.0 \%$ & $\mathbf{8 1 8}$ \\
\hline Incomplete & $\mathbf{8 5 . 5 \%}$ & $\mathbf{8 4 . 3 \%}$ & $\mathbf{8 8 . 3} \%$ & $\mathbf{5 , 1 7 1}$ \\
Completed & $14.5 \%$ & $15.7 \%$ & $11.7 \%$ & 683 \\
\hline
\end{tabular}

It is interesting, that when comparing the retention results $(14 \%)$ and terminal efficiency $(11.7 \%)$ of the course, the percentages are similar to those denoted by the University of Toronto which reported $8 \%$ average of terminal efficiency (Harrison, 2013), 10\% reported by Miriadax (SCOPEO, 2013), and 10\% reported by Lushnikova et al. (2013). 


\section{Features of Students who Completed the Course}

Researchers carried out a comparative analysis of the characteristics of the persons who abandoned the course against those who remained, and the features confrontation of those who completed the course and those who did not deliver the self-evaluation assessments. This analysis shows that the students who possess a master's degree or higher are more likely to remain in the course, rather than those who only have a professional degree or lower educational level (Table 4). The persons who did not have previous experience with online education had lower rates of completion and terminal efficiency (Figure 1).

Table: 4

MOOCs Terminal efficiency according to educational level

\begin{tabular}{lcc}
\hline Educational Level & Student's retention & Terminal efficiency \\
\hline High school & $11.4 \%$ & $10.7 \%$ \\
Technical career & $9.0 \%$ & $8.0 \%$ \\
Undergraduate degree & $14.4 \%$ & $12.1 \%$ \\
Master's degree & $19.0 \%$ & $15.9 \%$ \\
Doctorate & $20.1 \%$ & $17.2 \%$ \\
Post-doctorate & $28.2 \%$ & $23.1 \%$ \\
\hline
\end{tabular}

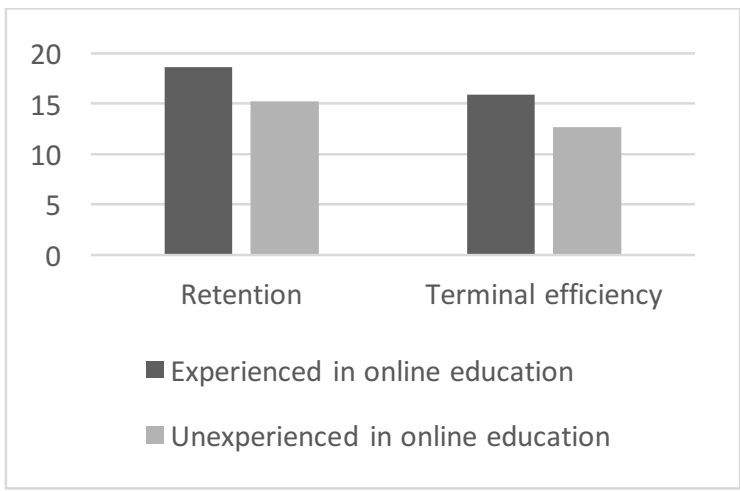

Figure: 1

Terminal efficiency in the MOOC according to experience with online courses.

Additionally, results show that the participants who expressed more initial commitment presented higher completion and terminal efficiency rates; these participants planned to complete all the activities and evaluations to obtain a diploma and registered to the course as a way to complement their previous studies. On the contrary, the people who registered out of curiosity or who were not committed to the activities registered lower completion and terminal efficiency rates. These results confirm the statements by Cabrol \& Székely (2012), regarding the importance of relevant education as a strategy to avoid academic failure and desertion. Likewise, Alemán, Sancho-Vinuesa y Gómez-Zermeño (2015) highlight the need for resource and strategy analysis under selection criteria.

Individuals who expressed to have economic stability, either full-time or part-time workers, business owners, at home work or people who have a flexible schedule, reported higher completion and terminal efficiency rates, as opposed to those who study in high school or a undergraduate degree.

It is important to mention that the participants who described themselves as self-learners obtained higher completion and terminal efficiency rates. 
Regarding the features of the participants with higher completion rates, they displayed a proficient use of information technologies, of digital resources design, intermediate English level, knowledge organization skills, participation in research networks, and other characteristics. In relation to the people who described themselves as pro-active, there were no significant differences in the results of completion and terminal efficiency.

On the contrary, the people without knowledge about copyrights, web information administration, use of OER in the classroom, and lack of experience in research networks presented higher abandonment of the course.

It must be noted that the previously mentioned characteristics have significant statistic differences, which were validated by the Pearson's chi-squared test, at $95 \%$ confidence interval.

\section{Causes of Dropout and Abandonment}

Coursera politics do not allow e-mail sharing in order to avoid spam. Therefore, it was not possible to administrate a sanctioned follow-up survey to explore the specific reasons some participants had when deciding to dropout or abandon the course. As an alternative, a reflection about various messages shared on the discussion forums was made. Among the stated reasons that may cause the discouragement of the participants and to abandon the course were:

$>$ Difficulties with the structure of the course, and lack of a tutorial to guide users.

$>$ The quality of the materials was also criticized.

$>$ Family reasons and no availability for the course.

$>$ Limitations on the use of information technology or in the English language.

$>$ Limitations of the Coursera platform.

\section{Probabilistic Model to Evaluate Terminal Efficiency of MOOC}

Given the results, the terminal efficiency of the MOOC was analyzed through the construction of a probabilistic model in order to quantify the weight of the main features of participants who do not complete the course. The main results of the models (table 5) are:

$>$ The odds of desertion of the MOOC increases $5.7 \%$ when the participant has an undergraduate or lower degree, and the probability rises $5 \%$ when the student does not have knowledge about copyrights. On the contrary, the odds of desertion diminishes $7 \%$ if the participant is older than 55 years old, $17 \%$ when they show a strong commitment to the MOOC and $4.2 \%$ when they have a full-time or part-time job

$>$ The odds to complete the MOOC increases by $3.2 \%$ when the participant is female and $3.8 \%$ when it has no copyrights knowledge. By contrast, the odds of not completing decreases $8 \%$ when participants are over $55,15 \%$ when they have a strong commitment, and another $3.2 \%$ when they are excited by applying course's knowledge in their practice as teachers or daily life. 
Table: 5

Probabilistic model of the participants who do not complete an MOOC

\begin{tabular}{|c|c|c|}
\hline Traits of the participant & Desertion & Dropout \\
\hline Female & 0.0187 & $0.0323 *$ \\
\hline Older than 55 years old & $-0.0698 *$ & $-0.0803 * *$ \\
\hline Experienced in online education & -0.02 & -0.015 \\
\hline Does not have a degree (high school or technician) & $0.0568 *$ & 0.0396 \\
\hline Full-time or part-time job & $-0.042 * *$ & -0.021 \\
\hline Plans to accomplish activities and tests to obtain certificate & $-0.1702 * *$ & $-0.1499 * *$ \\
\hline $\begin{array}{l}\text { Null }(0-20 \%) \text { - IT domain to create audio, video, images, } \\
\text { etc. }\end{array}$ & 0.0451 & 0.0423 \\
\hline Null $(0-20 \%)-$ Knowledge about copyrights & $0.0501 * *$ & $0.0382 *$ \\
\hline Not important - Research filters & -0.0491 & 0.0215 \\
\hline Null (0 - 20\%) I do not know the English language & 0.0271 & 0.0245 \\
\hline Lack of confidence - During information research & 0.0989 & 0.1115 \\
\hline Self-taught (Constantly updating my knowledge) & -0.0031 & -0.0165 \\
\hline $\begin{array}{l}\text { Null }(0-20 \%) \text { - Knowledge of use of techniques and } \\
\text { methods to organize knowledge in an accessible and } \\
\text { considering scientific objectives, observable facts, and / } \\
\text { or measurable }\end{array}$ & 0.003 & -0.0026 \\
\hline $\begin{array}{l}\text { Null }(0-20 \%) \text { - Domain to communicate in virtual } \\
\text { environments }\end{array}$ & -0.0756 & -0.0526 \\
\hline $\begin{array}{l}\text { Null }(0-20 \%) \text { - Domain to determine credibility of } \\
\text { information }\end{array}$ & 0.0001 & 0.042 \\
\hline $\begin{array}{l}\text { To complement my classes (design and/or prepare } \\
\text { courses) }\end{array}$ & -0.0226 & $-0.0316 *$ \\
\hline $\begin{array}{l}\text { Uncertain, because they do not know what students will } \\
\text { think of the use of open resources }\end{array}$ & -0.0085 & -0.0169 \\
\hline Does not participate in research network & 0.0306 & 0.022 \\
\hline $\begin{array}{l}\text { Not willing to participate as facilitator or Teaching } \\
\text { Assistant }\end{array}$ & 0.0092 & 0.0166 \\
\hline
\end{tabular}

For probabilistic models, the dependent variable is constrained between zero and one, being derived from the cumulative distribution function (Gujarati, 1997). One way of evaluating the probabilistic models is derived from the goodness of fit $\left(R^{2}\right)$; however, when dealing with nonlinear models the goodness of fit is meaningless in terms of the defined coefficient of determination. The pseudo $\mathrm{R}^{2}$ of the model to neglect and no completion corresponds to 0.0249 and $\mathbf{0 . 0 2 5 2}$, respectively. However, note that by supplementing with another statistic shows that the model correctly classifies drops to $75 \%$ of cases, whereas the model for not completed correctly classified $\mathbf{7 8} \%$ of instances. So the models can be considered quite acceptable for a multi factorial phenomenon as desertion and abandonment.

\section{CONCLUSIONS}

The main results of this research reveal low terminal efficiency rate of a MOOC, which was offered by a higher education institution. Although there was a positive response from the students, the percentage of participants who successfully completed the course indicates the opposite; therefore, it is important to study the reasons that led the participants to enroll and the causes of desertion. 
The MOOC analyzed in this study had a rate of $11.7 \%$ completion rate, which represents the number of students who delivered their respective assessments and answered throughout the course evaluations. In contrast, the high dropout rate of $86 \%$ agrees with the statements of Clow (2013), who mentions that the abandonment of online courses is higher than in classroom education. This result is parallel with the report of the University of Toronto, which showed a rate of approximately $8 \%$ of students who completed the course (Harrison, 2013). Similarly, Lushnikova et al. (2013) indicate that about $10 \%$ of the students who enrolled in a MOOC managed to complete the course. In this connection, Siemens and Tittenberger (2009) note that desertion rates can be minimized by upgrading the course components that lead to an increase in the motivation levels and better student-faculty relationships.

This study identified the main characteristics of the participants who managed to stay and complete the course, being favored those with graduate degrees, online educational previous experience, greater commitment to the course and economic stability. Other found features were the advanced or expert proficiency in the use of information technology, advanced proficiency in creating digital resources, intermediate English language skills, advanced proficiency in the use of techniques and methods to organize knowledge and active participation in research networks, among others. On the other hand, those who decided to leave the course indicated problems with the structure and guidance in the course, limitations on the use of information technology or in English, in addition to the limited availability of time due to family or work reasons. It is noteworthy that among the deserters were participants with a high school or bachelor education who do not participate in research networks, which is consistent with the statement made by Siemens (2005), who defines the research groups as a means to update the knowledge and maintain connections for continuous learning.

The results of the probabilistic models constructed to measure the weight of the characteristics of participants who drop out or fail to complete a MOOC course, reflect that the participants' likelihood to leave the MOOC course increases when the participant has a lower educational degree level and has no knowledge of copyrights. On the contrary, the probability of abandonment decreases when participants are over 55, have a strong commitment to the MOOC and when they have full or partial employment. In terms of completeness, the chances of not completing the MOOC increases when the participant is female and does not have any knowledge of copyrights. By contrast, the odds of not completing decreases when participants are over 55 when they have a strong commitment, and when they are excited by applying knowledge of the course in their practice as teachers or daily life.

In light of the results obtained in this research, two possible courses of action arise as strategies to increase the level of awareness of the terminal performance of MOOCs' participants: First, the application of surveys to students who decide to leave the course to obtain additional information about their reasons. Second, to increase the level of terminal efficiency of MOOCs, it is proposed to include in the course's structure items such as a welcome tutorial to guide novice users in this type of courses, on their function and structure; organize discussion forums by language, country or thematic affinities, and improve the quality of the videos and captions.

These recommendations are consistent with the approach of Aguaded (2013) who states the need to strengthen areas, such as interaction with the facilitators, collaborative and interactive work, respect cultural and linguistic diversity, for MOOC constituting an exceptional learning experience. Similarly, for the effectiveness of these courses you must create a scaffold to guide and help the participants to achieve their learning goals (Salmerón, Rodríguez, \& Gutiérrez2010).

This research enables institutions that offer MOOC courses to consider the characteristics of the participants, in order to achieve greater efficiency and lower desertion rates. Thus, the educational practices in MOOC will benefit by improving their implementation and continue gathering information on new experiences in such resources. 


\section{BIODATA and CONTACT ADDRESSES of the AUTHORS}

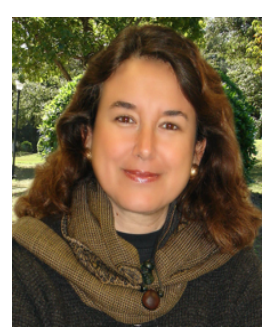

Prof. Dr. Marcela Gerogina GOMEZ-ZERMENO holds a doctorate in Educational Innovation from Tecnológico de Monterrey, and a master's degre in Information and Communication Technology Engineering Sciences. INT-CITCOM, France Télécoms Higher Education. She also holds a bachelor's degree in Computer and Administration Systems from ITESM. She is a tenured lecturer at Tecnologico de Monterrey's masters degree programs in Education and in Educational Technology, as well as on the doctoral program in Educational Innovation. She is a member of the the Mexican Education Research Council (COMIE). She is the technical manager on educational research projects of the Mexican National Council of Science and Technology (CONACYT) and on the ALFA program of the European Commission. She forms part of the National System of Researchers (SNI) Level 1.

Prof. Dr. Marcela Gerogina GOMEZ-ZERMENO

Tecnológico de Monterrey, Campus Monterrey,

Edificio CEDES, Ave. Eugenio Garza Sada, 2501 Sur,

CP 64849 Monterrey, N.L., MÉXICO.

Phone: +52 8116461430 .

Email: marcela.gomez@itesm.mx

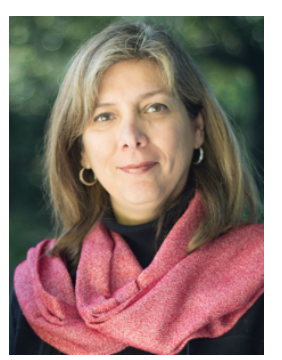

Lorena ALEMAN DE LA GARZA is a doctoral candidate on the Education and ICT (e-learning) doctoral program at the Open University of Catalonia (UOC), Spain. She holds a master's degree, with honors, in Educational Institution Administration from ITESM, and a bachelor's degree, with honors, in Business Administration from TecMilenio University, Mexico. She has worked as a postgraduate lecturer at Tecnológico de Monterrey's masters degree programs in Educational Institution Administration, in Education and in Educational Technology. She is the technical manager on educational research projects of the Mexican National Council of Science and Technology (CONACYT). She currently is the director of Continuing Education at Tecnológico de Monterrey.

\section{Lorena ALEMAN DE LA GARZA}

Tecnológico de Monterrey, Campus Monterrey,

Edificio CEDES, Ave. Eugenio Garza Sada, 2501 Sur,

CP 64849 Monterrey, N.L., MÉXICO.

Phone: +52 8116461435 .

Email: Iorena.aleman@itesm.mx

\section{REFERENCES}

Aguaded, J.I. (2013). La revolución MOOCs, ¿una nueva educación desde el paradigma tecnológico? Comunicar, 41, 07-08.

Alemán de la Garza, L.Y., Sancho-Vinuesa, T. \& Gómez-Zermeño, M.G. (2015). Indicadores para evaluar la calidad de un curso en línea masivo y abierto para la actualización docente. Revista Universidad y Sociedad del Conocimiento, 12(1), 104-118.

Alemán, L., \& Gómez-Zermeño, M. G. (2012). Liderazgo Docente para la Enseñanza de la Innovación. Revista de Investigación Educativa, 4(2), 2-7.

Cabrol, M. y Székely, M. (2012). Educación para la Transformación. Washington, DC: Banco Interamericano de Desarrollo. 
Clow, D. (2013). MOOCs and the Funnel of Participation. The Open University. Retrieved from http://dougclow.org/mooc-funnel/

Creswell, J. W. y Plano Clark, V. L. (2011). Designing and conducting Mixed Method Research (2a ed.). Thousand Oaks CA, USA: Sage.

Fini, A. (2009). The Technological Dimension of a Massive Open Online Course: The Case of the CCK08 Course Tools. The International Review Of Research In Open And Distance Learning, $10(5)$.

Gómez-Zermeño, M. G. (2012). Digital Libraries: Electronic Bibliographic Resources on Basic Education. Comunicar, 20(39), 119-126.

Gómez-Zermeño, M. G., Rodríguez Arroyo, J. A. y Márquez Guzmán, S. (2013). Estudio Exploratorio-Descriptivo "Curso Híbrido: Contabilidad V". Revista de Investigación Educativa de la Escuela de Graduados en Educación, 4(7), 70-79.

Gujarati, D. (1997). Econometría Básica. Colombia: McGraw Hill.

Harrison, L. (2013). Open UToronto MOOC Initiative: Report on First Year on Activity. Toronto: University of Toronto.

Liyanagunawardena, T., Adams, A., y Williams, S. (2013). MOOCs: A systematic study of the published literature 2008-2012. The International Review of Research in Open and Distance Learning, 14(3).

Lushnikova, N., Chintakayala, P. \& Rodante, A. (2013). Massive Open Online Courses from Ivy League universities: benefits and challenges for students and educators. XI International Conference "Providing continuity of content in the system of stepwise graduate and postgraduate education", Ukraine, November 15-16, 2012.

McAuley, A., Stewart, S., Siemens, G. y Cormier, D. (2010). The MOOC Model for Digital Practice. Canadá: University of Prince Edward Island.

Mortera, F. (2012). Internet, los Recursos Educativos Abiertos y el Movimiento Abierto. Red Latinoamericana Portales Educativos (RELPE). Retrieved from:

http://www.relpe.org/destacados/internet-los-recursos-educativos-abiertos-y-elmovimiento-abierto/

Rodríguez, 0. (2012). MOOCs and the AI-Stanford like Courses: Two Successful and Distinct Course Formats for Massive Open Online Courses. European Journal of Open, Distance and E-Learning. Retrieved from: http://files.eric.ed.gov/fulltext/EJ982976.pdf

Salmerón, H., Rodríguez, S. y Gutiérrez, C. (2010). Metodologías que optimizan la comunicación en entornos de aprendizaje virtual. Comunicar, 34, 163-171. DOI: 10.3916/C34-2010-03-16.

SCOPEO (2013). MOOC: Estado de la situación actual, posibilidades, retos y futuro. Scopeo Informe No. 2.

Siemens, G. (2005). Connectivism: A learning theory for the digital age. International journal of instructional technology and distance learning, 2(1), 3-10.

Siemens, G. y Tittenberger, P. (2009). Handbook of Emerging Technologies for Learning. Retrieved from: http://elearnspace.org/Articles/HETL.pdf

UNESCO (2002). Forum on the impact of open courseware for higher education in developing countries: final report. Paris: UNESCO.

UNESCO (2012). Declaración de París de 2012 sobre los REA. Congreso Mundial sobre los Recursos Educativos Abiertos (REA). Paris: UNESCO. 
Valenzuela, J. R. y Flores, M. (2012). Fundamentos de investigación educativa, Volumen 2. Monterrey, México: Editorial Digital Tecnológico de Monterrey.

Wiley, D., \& Hilton III, J. (2009). Openness, Dynamic Specialization, and the Disaggregated Future of Higher Education. The International Review of Research in Open and Distance Learning, 10(5). 